\title{
Imaging of shear wave attenuation along the central part of the North Anatolian Fault Zone, Turkey
}

\author{
Peter Gaebler (i) . Tuna Eken • \\ Hüseyin Önder Bektaş • Tom Eulenfeld · \\ Ulrich Wegler • Tuncay Taymaz
}

Received: 24 August 2018 / Accepted: 22 May 2019 / Published online: 10 June 2019

(C) The Author(s) 2019

\begin{abstract}
This study investigates the 2D-lateral distribution of frequency-dependent crustal seismic attenuation parameters beneath the central part of the North Anatolian Fault Zone in Turkey. Parameter estimations are based on an optimal fit between observed and synthetically computed seismogram envelopes in four different frequency bands ( 1.5 to $12 \mathrm{~Hz}$ ). The forward modeling of the synthetic data relies on acoustic radiative transfer theory under the assumption of multiple isotropic scattering. Lateral variations of intrinsic and scattering attenuation clearly separate the main
\end{abstract}

Electronic supplementary material The online version of this article (https://doi.org/10.1007/s10950-019-09842-1) contains supplementary material, which is available to authorized users.

\section{P. Gaebler $(\bowtie)$}

BGR Federal Institute for Geosciences and Natural Resources, Stilleweg 2, 30655 Hannover, Germany e-mail: peter.gaebler@bgr.de

T. Eken · T. Taymaz

Department of Geophysical Engineering, The Faculty of Mines, Istanbul Technical University, Maslak 34469, Istanbul, Turkey

H. Ö. Bektaş

Department of Electronics and Communication Engineering, The Faculty of Electrical and Electronics, Istanbul Technical University, Maslak 34469,

Istanbul, Turkey

T. Eulenfeld · U. Wegler

Institute of Geosciences, Friedrich Schiller University, Burgweg 11, 07749 Jena, Germany branch of the central part of the fault zone. Comparisons between intrinsic and scattering attenuation imply that seismic energy loss in the region of the central part of the North Anatolian Fault Zone is clearly dominated by the process of intrinsic attenuation. As a by-product of the inversion, moment magnitudes of the investigated events are calculated. Comparison of coda-derived magnitudes with magnitudes obtained from the earthquake catalog indicate that the analytical inversion approach can successfully be applied, even in this tectonically complex regime.

Keywords Intrinsic and scattering attenuation . Acoustic radiative transfer theory $\cdot$ North Anatolian Fault Zone · Turkey

\section{Introduction}

The North Anatolian Fault Zone (NAFZ) is regarded as one of the largest plate bounding transform faults and separates the Anatolian Plate to the south from the Eurasian Plate to the north. To describe and better understand the propagation of seismic waves in that region, a profound knowledge of the Earth's heterogeneous subsurface between source and receiver is required. In addition to the commonly investigated parameters such as seismic velocity or anisotropy, information about the seismic attenuation parameters of the medium is of great importance. Attenuation is expressed by the decrease of seismic wave ampli- 
tude and is mainly caused by three factors. The first factor is energy loss due to geometrical spreading of the seismic waves from the source into a spherical wavefront. The second mechanism responsible for the decrease in seismic wave amplitude is intrinsic attenuation. The propagation of seismic waves is not completely elastic and consequently small fractions of wave energy are converted into other forms of energy, such as mineral dislocations or frictional heat. The third parameter, which contributes to the apparent attenuation of seismic waves, is scattering attenuation. This mechanism can be described as the redistribution of seismic energy at 3D-heterogeneities of the subsurface medium. These scattering events generate the seismic coda, the part of the seismic signal recorded after the passage of the direct phase arrivals (Aki 1969; Aki and Chouet 1975). Numerous studies in the past suggested that unlike direct waves, highfrequency scattered waves are more or less insensitive to source radiation pattern effects due to an averaging of coda waves that sample the entire focal sphere (Aki 1969; Aki and Chouet 1975; Mayeda and Walter 1996; Eken et al. 2004). Due to the fact that the coda wave amplitude is proportional to the excitation of the source, the use of coda waves to extract information about the seismic source has recently become popular. Coda wave amplitudes derived from a recent empirical coda normalization approach using local and regional earthquakes have been found to be three to four times more robust than those obtained from the direct phases (Yoo et al. 2011). A comprehensive review for multiple theoretical and observational approaches for the analysis of coda waves can be found in Sato et al. (2012). Several approaches are routinely used for the separation of intrinsic and scattering attenuation. One approach is referred to as diffusion approximation and is based on the assumption of strong multiple scattering and can only be applied for long lapse times (Dainty et al. 1974; Wegler and Lühr 2001). A further commonly used method to investigate the attenuation parameters is radiative transfer theory (RTT), a method first introduced by Chandrasekhar (1960) to describe the transport of light in the turbulent atmosphere and which was only later transferred to the field of seismology (Weaver 1990; Turner and Weaver 1994; Ryzhik et al. 1996). Two main branches of this method were developed for the purpose of seismic attenuation imaging. A majority of studies use the approach of isotropic acoustic scattering of seismic energy, an approach which only simulates the propagation of shear wave energy under the assumption of scattering with no preferred direction. One method that is using this approach as forward algorithm is multiple lapse time window analysis (MLTWA). MLTWA is applying coda normalization and uses energy ratios calculated from averaged data in multiple time windows to estimate attenuation parameters. Detailed information for studies employing the MLTWA can be, for example, found in Fehler et al. (1992), Hoshiba (1993), or Carcolé and Sato (2010). A further approach uses isotropic acoustic RTT to directly fit synthetic and observed coda and a time window for the direct $\mathrm{S}$-wave. This approach does not rely on coda normalization. For studies applying this approach, see for example Sens-Schönfelder and Wegler (2006) or Eulenfeld and Wegler (2016). The assumption of anisotropic scattering was further incorporated in the approach of RTT and was for example used by Gusev and Abubakirov (1987). This development allowed the modeling of forward scattering and consequently the simulation of peak broadening effects of the direct seismic wave arrivals. The second branch of studies deals with the modeling of elastic energy propagation (Zeng 1993; Przybilla and Korn 2008; Sens-Schönfelder et al. 2009; Gaebler et al. 2015b) and subsequently allows including the propagation of P-energy as well as conversion effects between $\mathrm{P}$ - and S-energy. In this study, we simultaneously invert for attenuation parameters, as well as source and site effects using the approach of acoustic RTT under the assumption of multiple isotropic scattering without having to apply a coda normalization method. The choice of isotropic scattering is justified also for an anisotropic scattering regime. This was shown in a study by Gaebler et al. (2015a), in which results from more complex elastic RTT simulations yielded nearly identical results as simulations based on a simpler approach using acoustic isotropic RTT. These findings allow us to rely on the concept of acoustic isotropic RTT, even in this very heterogeneous and complex tectonic regime developed under intense active deformation.

\section{Study area and data}

Section 2.1 briefly summarizes the tectonic and geological setting of the NAFZ, and some previous studies 
focusing on the region of interest are presented in Section 2.2. Information about the utilized seismic data and station details can be found in Section 2.3.

\subsection{The North Anatolian Fault Zone}

The Cenozoic closure of the Tethys ocean and the following convergent plate motions (for example the continental collision of the Arabic Plate with the Eurasian plate) are considered to be responsible for shaping the recent tectonic settings of the eastern Mediterranean and Anatolia (Dewey and Şengör 1979; Taymaz et al. 1990; Taymaz et al. 2004). See Fig. 1 for an overview of the tectonic settings of Anatolia and of the surrounding regions.

The NAFZ and the East Anatolian Fault Zone (EAFZ) represent the major plate boundaries along which the strain localization controls the current deformation. The NAFZ is an intercontinental right lateral (dextral) strike-slip fault of $1600 \mathrm{~km}$ length between the Eurasian plate in the north and the Anatolian plate in the south. The present work focuses on seismic attenuation characteristics within the crustal portion of the central NAFZ consisting out of various converging tectonic blocks such as the Central Pontides, the Istanbul Zone, the Intra-Pontides, the Izmir-Ankara-Erzincan Suture Zones (IAESZ), the Kırşehir Massif, the Ezine Pazari-Sungurlu Fault, and the Çankırı Basin (Kaymakçı et al. 2000). Two characteristic geological features are the Pontides to the north, which are considered as the eastern follow-up of the Rhodope-Pontide fragments and the Çankırı Basin consisting of an upper Cretaceous ophiolitic melange and granitoids (Robertson et al. 2009). A more than 4-km-thick sedimentary infill ranging from Late Cretaceous to present age is typical for that basin.

\subsection{Previous investigations of crustal properties in the study area}

Recently conducted temporary passive seismic experiments in the region have greatly contributed to an increase of knowledge of the crustal structure. They shed light into unknown seismic $\mathrm{P}$ - and $\mathrm{S}$-wave speed variations as well as the geometry of discontinuities in crust and mantle. Investigations of the lateral distribution of the coda wave quality factor $Q_{c}$ estimated in five subregions along the NAFZ from east to west have shown that the largest change of $Q_{c}$ with lapse time was observed at the western edge in the Yalova-Saros region. This emphasizes the significance of regional heterogeneity (Sertcelik and Guleroglu 2017). The analysis of converted waves showed that crustal thickness varies between 35 and $40 \mathrm{~km}$ (Vanacore et al. 2013). Findings on crustal thicknesses from an offshore seismic survey implied that the crust could be much thinner (25 to $30 \mathrm{~km}$ ) towards the west in the Marmara Sea region (Laigle et al. 2008). Seismic activity in Central Anatolia is not only associated to the main branch of the NAFZ. There are several moderate earthquakes, for example the 2000 Orta earthquake (Taymaz et al. 2007) or the 2005 and 2008 Balâ-Sırapınar earthquakes (Çubuk et al. 2014) that are distributed widespread in the southern block as the possible indication for ongoing internal deformation across the Anatolian Plate. Using the inversion of travel time, residuals extracted from the seismic activity (Yolsal-Çevikbilen et al. 2012) have reported pronounced P-wave velocity heterogeneities of up to $6 \%$ in the central part of the NAFZ. Results from Pnphase traveltime inversions exhibited average Pn-wave velocities of around $7.9 \mathrm{~km} / \mathrm{s}$ with average velocity fluctuations of $0.1 \%$ along the strike of the NAFZ (Gans et al. 2009). This is consistent with the shear wave velocity distribution at $50 \mathrm{~km}$ depth in a recent multi-scale waveform tomographic inversion (Fichtner et al. 2013a, b; Çubuk-Sabuncu et al. 2017) as well as with $\mathrm{S}$-wave velocity perturbations resolved within the inversion of ambient noise data (Delph et al. 2015). Most recently, based on azimuthal variations of Pto S-converted waves, Licciardi et al. (2018) reported a clear asymmetric distribution of crustal properties between the northern and southern blocks divided by the NAFZ. They observed more heterogeneous and stronger anisotropic behavior in the southern block while in the north, a simple and weakly anisotropic crust is typically observed.

\subsection{Earthquake data and station network}

The waveform data used in this study was recorded within the framework of the North Anatolian Fault passive seismic experiment, a joint project between the University of Arizona, Istanbul Technical University, Middle East Technical University, and Boğazici University (Kandilli Observatory and Earthquake Research Institute) (Beck and Zandt 2005). The continuous waveform data of this experiment can be 


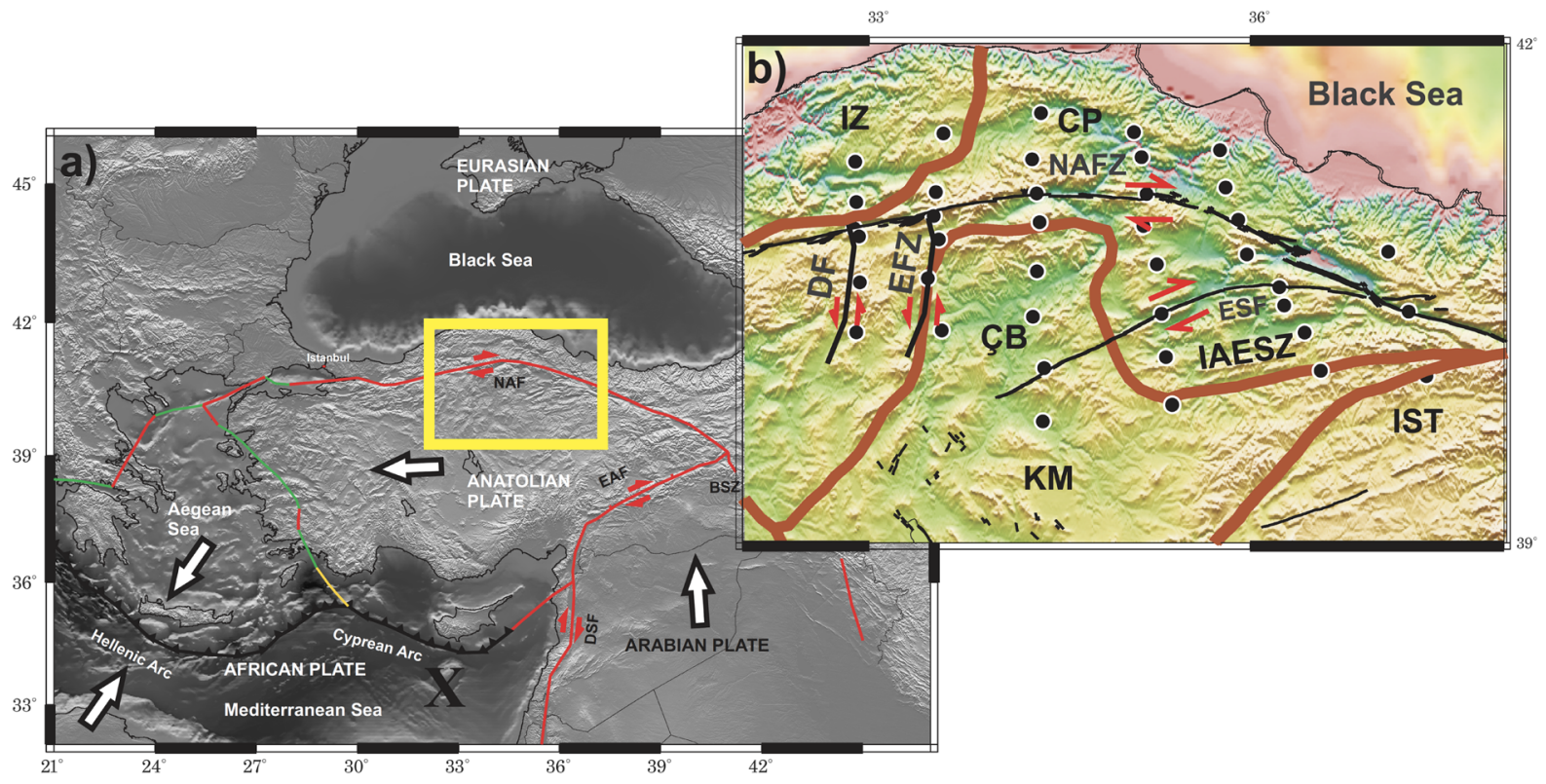

Fig. 1 a Tectonic settings of Anatolia and surrounding regions. Yellow rectangle highlights the study region. Major plate and geological elements of the study area (ESF, EzinepazarSungurlu Fault; DF, Dodurga Fault; EFZ, Eldivan Fault; IZ, Istanbul Zone; CP, Central Pontides; ÇB, Çankırı Basin; KM, boundary data are taken from Bird (2003). b Major tectonic

Kırşehir Massif; IAESZ, İzmir-Ankara-Erzincan Suture Zone; IST, Intra-Tauride Suture; NAFZ, North Anatolian Fault Zone). The tectonic boundaries are taken from Okay and Tüysüz (1999). White framed black circles indicate the 39 broadband seismic stations used in this study

\section{Inversion using acoustic radiative transfer theory}

tained by the Incorporated Research Institutions for Seismology (IRIS). We used seismic data from 35 out of 39 broadband stations in the time frame from January 2006 until May 2008. Data from four of the stations could not be used in the inversion process due to low signal-to-noise-ratios at that particular stations. Overall, 1422 waveforms with high-quality S-wave signals from 172 local events were used in the inversion process. Local magnitudes $M_{L}$ of the events range from 3.0 to 5.0, epicentral distances of the used waveforms are in the range from 0 to $120 \mathrm{~km}$, to avoid first arrivals from guided Sn-waves. Only events in depth range between 0 and $10 \mathrm{~km}$ were used for the estimation of the attenuation parameters. This is to ensure that the coda waves mainly sense the upper crust and do not reflect the attenuation parameters of the lower crust or upper mantle. Earthquake parameters, such as hypocenter location, source-time, and magnitudes, were reported by the Turkish Disaster and Emergency Management Authority (AFAD). An overview of station and event locations is presented in Fig. 2.
The inversion procedure consists of two steps. First, for each analyzed earthquake and all nearby stations, attenuation parameters and spectral source densities are determined at different frequencies using acoustic RTT. Second, the attenuation results for different events are averaged at each station and interpolated between station locations. In this study, we simultaneously invert for the intrinsic absorption parameter $b$, the transport scattering coefficient $g^{*}$, the dimensionless energy site amplification factor $R$, and the spectral source energy $W$ in Joule/Hz by solving a least squares linear equation system. Bounds for $b$ and $g^{*}$ are $10^{-9}$ to $10^{-2}$ and $10^{-4}$ to $10^{1}$, respectively. The details of the inversion method are comprehensively described in Eulenfeld and Wegler (2017). Here, we only give a summary of the processing steps and specify the parameters employed in the present study. For each earthquake, we use data of stations with a distance smaller than $120 \mathrm{~km}$. Data is filtered with a Butterworth bandpass filter in octave frequency bands with central frequencies at 1.5, 3.0, 6.0, and 


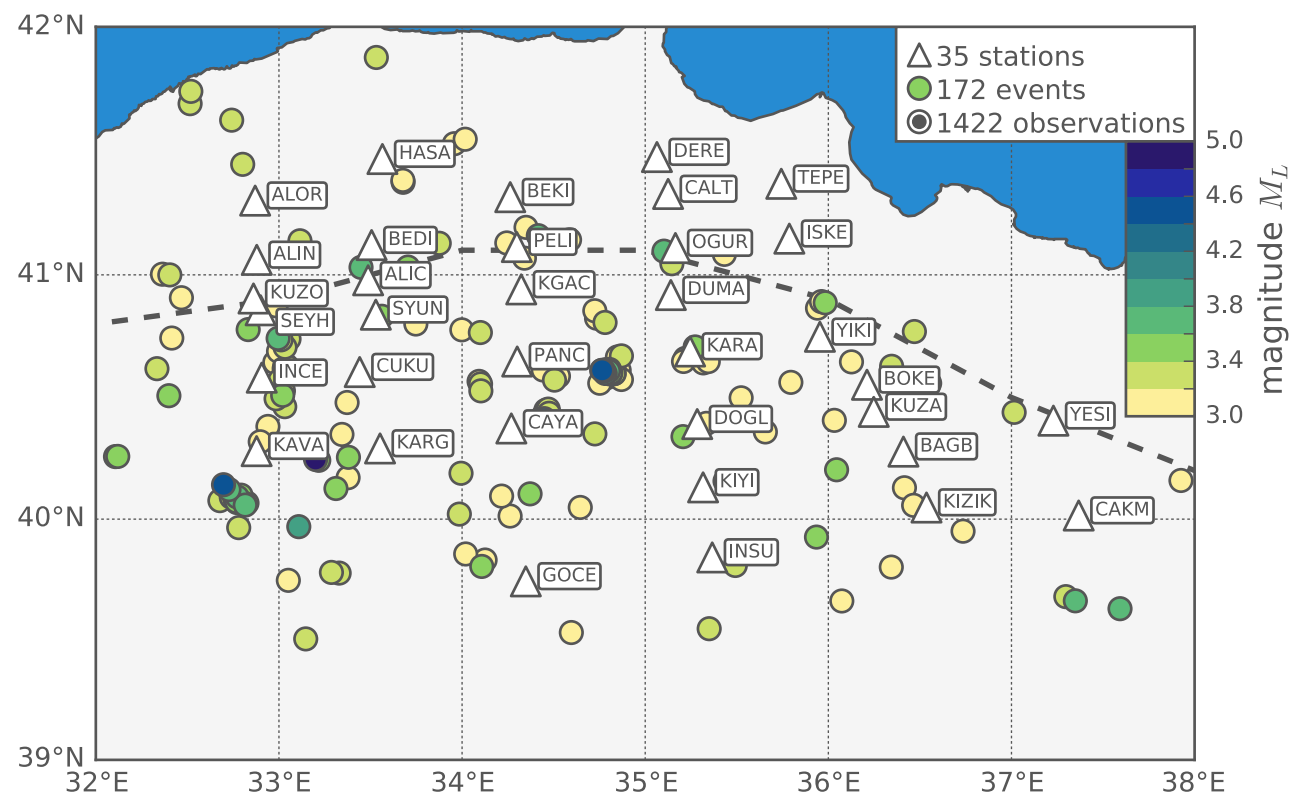

Fig. 2 Locations of the 35 broadband stations (triangles) and the 172 events (circles) used in this study. Event colors indicate magnitude, gray dashed line represents the central part of the NAFZ. A total of 1422 observations are used in the inversion process

12.0 Hz. Each frequency band is inverted separately. Total energy envelopes from the full seismograms of the three components at each station are calculated with the help of the Hilbert transform. The envelope noise level before the P-wave arrival is removed from the data. Preliminary S-wave arrivals are calculated using a local S-wave velocity model compiled from Delph et al. (2015). As no phase picks are available, the S-wave window is chosen rather broad to ensure that it includes all direct S-wave energy and starts $3 \mathrm{~s}$ before the S-wave arrival and ends $5 \mathrm{~s}$ afterwards. The coda window is defined to start at the end of the Swave window and has a maximum length of $95 \mathrm{~s}$. The coda window might be shorter if signal to noise ratio falls under a level of three or if the smoothed envelope does not decline with time but starts rising again (for example due to an aftershock). Waveform data of stations with coda windows shorter than $20 \mathrm{~s}$ are not used in the inversion, though. If data of less than three stations is available, the corresponding frequency band is completely removed from the analysis for this event. Furthermore, to clearly mark the boundary between the northern and southern part of the NAFZ, only station-event-pairs that are both located either north or south of the NAFZ are used in the inversion process. Stations on the opposite site of the NAFZ as the investigated event are discarded and not used in the inversion. Theoretical envelopes are calculated based on Eulenfeld and Wegler (2016, eq. 1):

$E_{\text {mod }}\left(t, \mathbf{r}_{i}\right)=W R_{i} G\left(t, \mathbf{r}_{i}, g^{*}\right) e^{-b t}$

where $i, t$, and $\mathbf{r}_{i}$ represent station index, lapse time, and the distance vector pointing from the hypocenter to the station location, respectively. $G$ is the scattering Green's function of the envelope given by acoustic radiative transfer (Paasschens 1997). The theoretical envelopes are fitted to the observed envelopes on a logarithmic scale. The fitting parameters are $b, g^{*}$, and $R_{i} \cdot W$. Several trade-offs between the different fitting parameters exist. In general, there is a perfect tradeoff between $R_{i}$ and $W$ in Eq. 1. This trade-off can be resolved by fixing the geometric mean of $R_{i}$ to 1 $\left(\Pi R_{i}=1\right)$. From Eq. 1, we expect a moderate tradeoff between $W$ and $b$. Trade-offs between $g^{*}$ and all other parameters are expected to be rather small due to the fact that the value of $g^{*}$ is basically fixed by the energy ratio of the direct $\mathrm{S}$-wave and the level of the coda waves. Attenuation parameters $b$ and $g^{*}$ are directly related to $Q_{i}^{-1}$ and $Q_{s}^{-1}$ (Gaebler et al. 2015a; Eulenfeld and Wegler 2017):

$$
Q_{s}^{-1}=\frac{g^{*} v_{0}}{2 \pi f} \quad Q_{i}^{-1}=\frac{b}{2 \pi f} .
$$


The parameter $f$ denotes frequency, and $v_{0}$ is the mean S-wave velocity, which is obtained from a local S-wave velocity model by Delph et al. (2015). Data in the $\mathrm{S}$-wave window is averaged and weighted with the length of the S-wave window. Data in the coda window is smoothed with a 1-s Bartlett window. The reasoning behind the special handling of the S-wave window is that effects of anisotropic scattering are not correctly described by the employed acoustic Green's function near the direct $\mathrm{S}$-wave arrival. For example fits between observed and modeled envelopes, we refer the reader to Figs. 3 and 4. In the second step, we follow the procedure described in Eulenfeld and Wegler (2017). The calculated observables $Q_{i}^{-1}$ and $Q_{s}^{-1}$ are assigned to the stations used in the particular inversion. After that, values for each station are averaged and interpolated between station locations. Results for the spatial distribution of $Q_{i}^{-1}$ and $Q_{s}^{-1}$ are given in Section 4.

\section{Results of the inversion process}

Example fits between synthetic and observed envelopes demonstrate the performance of our inversion and are presented in Section 4.1. A comparison of magnitudes obtained in the inversion and from the catalog is given in Section 4.2. Finally in Section 4.3, we present the 2D-lateral distribution of intrinsic and scattering attenuation that is individually estimated at each station.

\subsection{Example data fits}

To model the synthetic envelopes, the method of acoustic RTT is applied; therefore, it is only possible to model the propagation of S-wave energy. Consequently, only the fit between the direct S-wave arrival as well as the fit between the seismic coda following the direct $\mathrm{S}$-wave arrival of the synthetic and observed data can be determined. This is justifiable as S-wave energy dominates most of the seismic signal, mainly from the direct arrival of the S-wave to the late parts of the seismic coda (Ryzhik et al. 1996; Gaebler et al. 2015b). In Fig. 3, envelope fits for four different events with different local magnitudes $\left(M_{L} 3.0,3.1\right.$, 3.2 , and 4.0) and different frequency bands (1.5, 3.0, 6.0 , and $12.0 \mathrm{~Hz}$ ) are presented.
For all magnitudes and frequency bands, the direct onset of the S-wave can be modeled with high accuracy in terms of amplitude of the envelopes. The decay of the seismic coda for time windows of up to 50-75 s can be modeled with high accuracy as well. Note the faster decay of the seismic coda for higher frequencies. The overall quality of data fits is comparable with fits presented in Gaebler et al. (2015a) and Eulenfeld and Wegler (2016). Figure 3 clearly displays that for different regions of the study area and for events with different magnitudes, the observed data can be well described with the model data. Figure 4 additionally shows the fits in the remaining frequency bands for event 1 not shown in Fig. 3 and points out that fits are acceptable across all frequencies for one individual event.

\subsection{Magnitude comparison}

As a side product of the inversion, additionally to the attenuation parameters, the moment magnitude $M_{w}$ for each individual earthquake in our dataset is estimated by taking the geometric mean of the source displacement spectrum at frequencies smaller than $6 \mathrm{~Hz}$. For further details on the computation of $M_{w}$, the reader is referred to Eulenfeld and Wegler (2016). Figure 5 shows a comparison between $M_{w}$ estimated during the inversion process and local Richter magnitudes obtained from AFAD.

In general, a good agreement between both types of magnitudes can be observed. This indicates that the modeling of scattered S-waves using acoustic RTT under the assumption of multiple isotropic scattering is appropriate to relate the amplitude and the decaying character of the coda wave envelopes to the seismic moment of the source. Routinely determined magnitudes such as $M_{L}$ or $m_{b}$ are calculated from phase amplitudes and are strongly sensitive to source radiation patterns and lateral variations along the path (Pasyanos et al. 2016). $M_{w}$, in contrast to $M_{L}$, essentially represents a direct measure of the strength of an earthquake caused by fault slip and is estimated from a relatively flat portion of the source spectra at low frequencies. For these low frequencies, seismic attenuation is not drastically affected by near-surface structure (Ristau et al. 2003). Earlier coda wave studies performed on local and regional earthquakes in the region (Eken et al. 2004; Gök et al. 2016) utilized an 

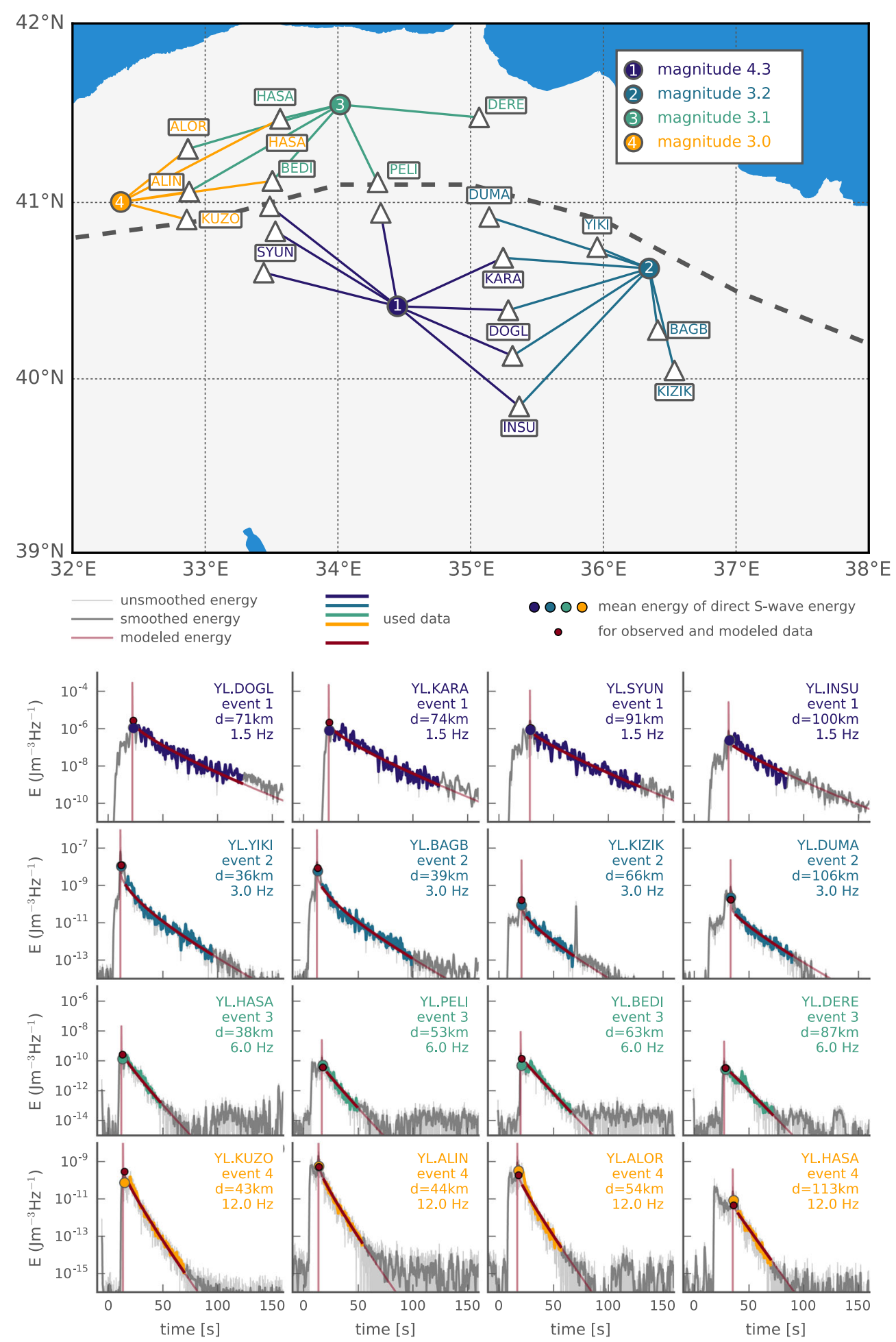

Fig. 3 Example fits of observed and synthetic envelopes for four different earthquakes with varying magnitude and four different frequency bands. Annotated stations (triangles) are shown in the bottom part of the figure, and non-annotated stations are used in the inversion process, but are not shown in the example envelopes. Frequencies increase from top to bottom, and magnitudes of the example events decrease from top to bottom 


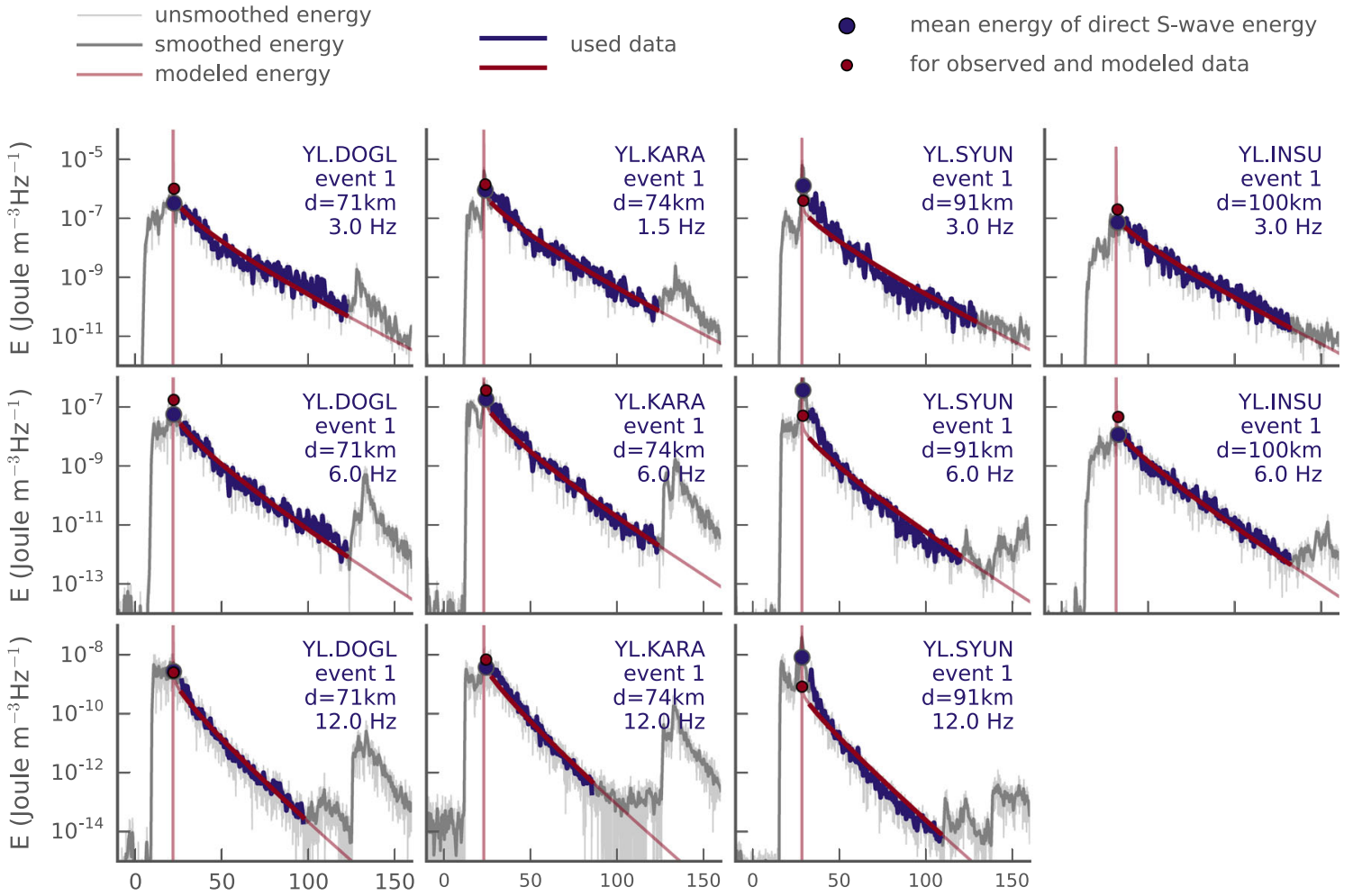

Fig. 4 Same as Fig. 3, but fits are shown for three remaining frequency bands (3, 6, and $12 \mathrm{~Hz}$ ) of event 1 (see Fig. 3)

empirical coda waves approach that assumes a simple 1-D radially symmetric spath correction. Furthermore, the amplitude-distance relationships were examined using coda waves based on 2-D path-corrected station techniques earlier employed in Mayeda et al. (2005) and Phillips et al. (2014) to improve the resolution
Fig. 5 Comparison of catalog local magnitudes and moment magnitudes estimated during the inversion process

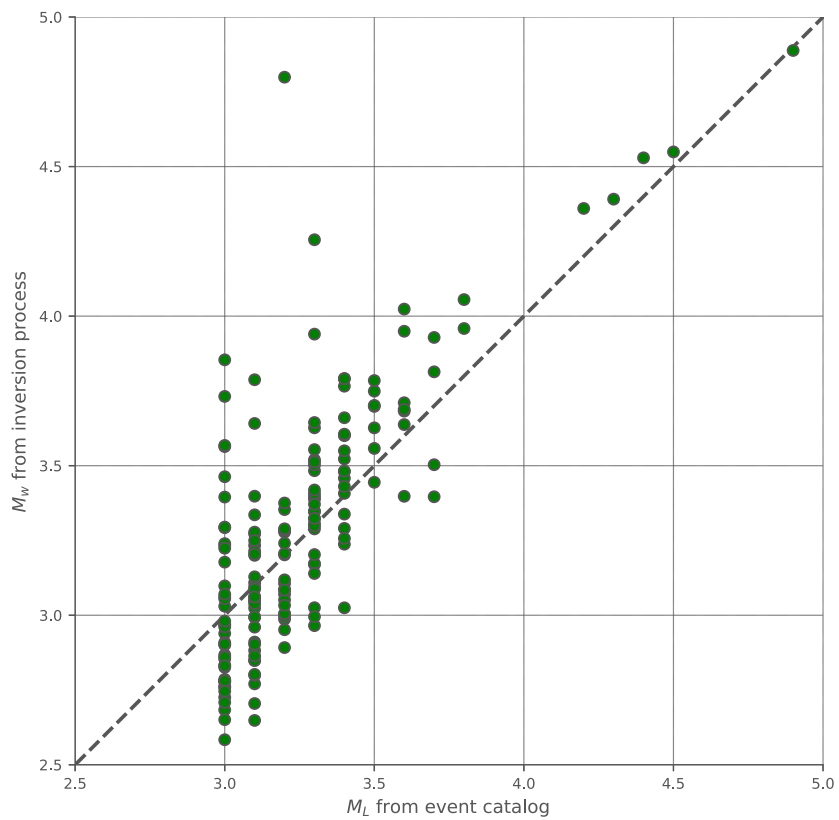


of earthquake source parameters. Resultant magnitude estimates showed a good accordance with the estimates from regional moment tensor inversions for the same events. In this study, we do not have too many earthquakes with $M_{w}>3.5$ but for available ones, we observe a promising correlation with the corresponding local magnitudes. A good correlation between coda-derived magnitudes with either moment or local magnitude scales for the earthquakes with $M_{w}>3.5$ suggests that empirical or non-empirical (this study) coda envelope fitting algorithms successfully worked in this tectonically complex region. In Fig. 5, it can be observed that the correlation between $M_{L}$ and $M_{w}$ gets worse for smaller events. This could be explained by the fact that direct waves of small events are more subject to near-surface attenuation effects due to their higher frequency content. Therefore, their amplitude measurements for $M_{L}$ cannot easily be related to the seismic moment. Furthermore, small errors during the inversion in the estimation of the other parameters $\left(Q_{i}^{-1}, Q_{s}^{-1}\right)$ may also lead to errors in the estimation of the moment magnitude.

\subsection{Intrinsic and scattering attenuation}

The 2D-lateral distribution of intrinsic, scattering, and total attenuation is presented in Fig. 6 .

For the entire study area, our method yields values from 0.0015 in the $12 \mathrm{~Hz}$ band up to 0.008 in the $1.5 \mathrm{~Hz}$ band for the inverse of the intrinsic quality factor $Q_{i}^{-1}$. Values for the inverse of the scattering quality factor $Q_{s}^{-1}$ are in the range from 0.0005 at $12 \mathrm{~Hz}$ up to 0.004 at $1.5 \mathrm{~Hz} . Q_{i}^{-1}$ and $Q_{s}^{-1}$ can be summed up in a value $Q_{t}^{-1}$ which is representative for the total attenuation of seismic waves. $Q_{t}^{-1}$ is in the range from 0.002 in the $12 \mathrm{~Hz}$ band up to 0.011 in the $1.5 \mathrm{~Hz}$ band. While in the northern part, values for $Q_{i}^{-1}$ are in the range from 0.002 at $12 \mathrm{~Hz}$ to 0.007 at $1.5 \mathrm{~Hz}$, and values are lower in the southern part of the NAFZ ranging from 0.0018 in the $12 \mathrm{~Hz}$ band up to 0.0058 in the $1.5 \mathrm{~Hz}$ band. For $Q_{s}^{-1}$, values in the north range from 0.0009 at $12 \mathrm{~Hz}$ up to 0.003 at $1.5 \mathrm{~Hz}$; in the southern part, values are slightly lower and range between 0.0097 at $12 \mathrm{~Hz}$ and 0.0029 at $1.5 \mathrm{~Hz}$. This translates into values for the total attenuation $Q_{t}^{-1}$ of 0.003 at $12 \mathrm{~Hz}$ up to 0.0103 at $1.5 \mathrm{~Hz}$ in the northern part. Values for $Q_{t}^{-1}$ in the southern part consequently are in the range from 0.0025 at $12 \mathrm{~Hz}$ up to 0.0087 in the $1.5 \mathrm{~Hz}$ band. Attenuation values at the individual stations are average values calculated from several inversion runs of different earthquakes. The deviations are calculated in terms of the median absolute deviation in percent from the individual attenuation measurements at the stations to the average values for the different frequency bands. For $Q_{i}^{-1}$, the median absolute deviations are in the range from 4 to $20 \%$ for $1.5 \mathrm{~Hz}$, from 2 to $16 \%$ for $3.0 \mathrm{~Hz}$, from 4 to $12 \%$ for $6.0 \mathrm{~Hz}$ and from 8 to $20 \%$ for $12.0 \mathrm{~Hz}$. For $Q_{s}^{-1}$, the values range from 3 to $33 \%$ for $1.5 \mathrm{~Hz}$, from 10 to $30 \%$ for $3.0 \mathrm{~Hz}$, from 10 to $40 \%$ for $6.0 \mathrm{~Hz}$, and from 20 to $40 \%$ for $12.0 \mathrm{~Hz}$. An overview of the values for the median absolute deviation in percent for $Q_{i}^{-1}$ and $Q_{s}^{-1}$ is given in Fig. 7.

It is visible that deviations for $Q_{s}^{-1}$ are significantly higher than the deviations for $Q_{i}^{-1}$. The estimation of $Q_{i}^{-1}$ is very robust, as it is mainly related to the stable decay of the seismic coda. In contrast, the estimation of $Q_{s}^{-1}$ is more susceptible to uncertainties, as it relies on the energy ratio of the direct $\mathrm{S}$-wave and the coda wave. Despite the relatively high median absolute deviations, our method still yields reliable results for $Q_{i}^{-1}$ and $Q_{s}^{-1}$, as we average over a large number of inversion results. For further information on the stability of the inversion method, we refer the reader to the Supplementary Material of this manuscript. An overview of the aforementioned values for $Q_{i}^{-1}, Q_{s}^{-1}$, and $Q_{t}^{-1}$ for the northern and southern part of the NAFZ is presented in Fig. 8.

The frequency dependence of the total attenuation (see right part of Fig. 8) follows a best fitting power law of $0.013 \times f^{-0.67}$ for the blocks north of the NAFZ and $0.011 \times f^{-0.71}$ for the blocks south of the NAFZ. These values are comparable with findings from Eulenfeld and Wegler (2016), who investigated seismic attenuation parameters for geothermal reservoirs in Germany for frequencies between 1 and $70 \mathrm{~Hz}$. Our results suggest that over the entire study region, intrinsic attenuation is clearly dominant over scattering attenuation. Amounts of attenuation resolved in this study are comparable with results for crustal structure estimated in other studies (SensSchönfelder and Wegler 2006; Carcolé and Sato 2010; Calvet and Margerin 2013; Gaebler et al. 2015a). For an overview over crustal intrinsic and scattering attenuation parameters, we refer the reader to the sup- 

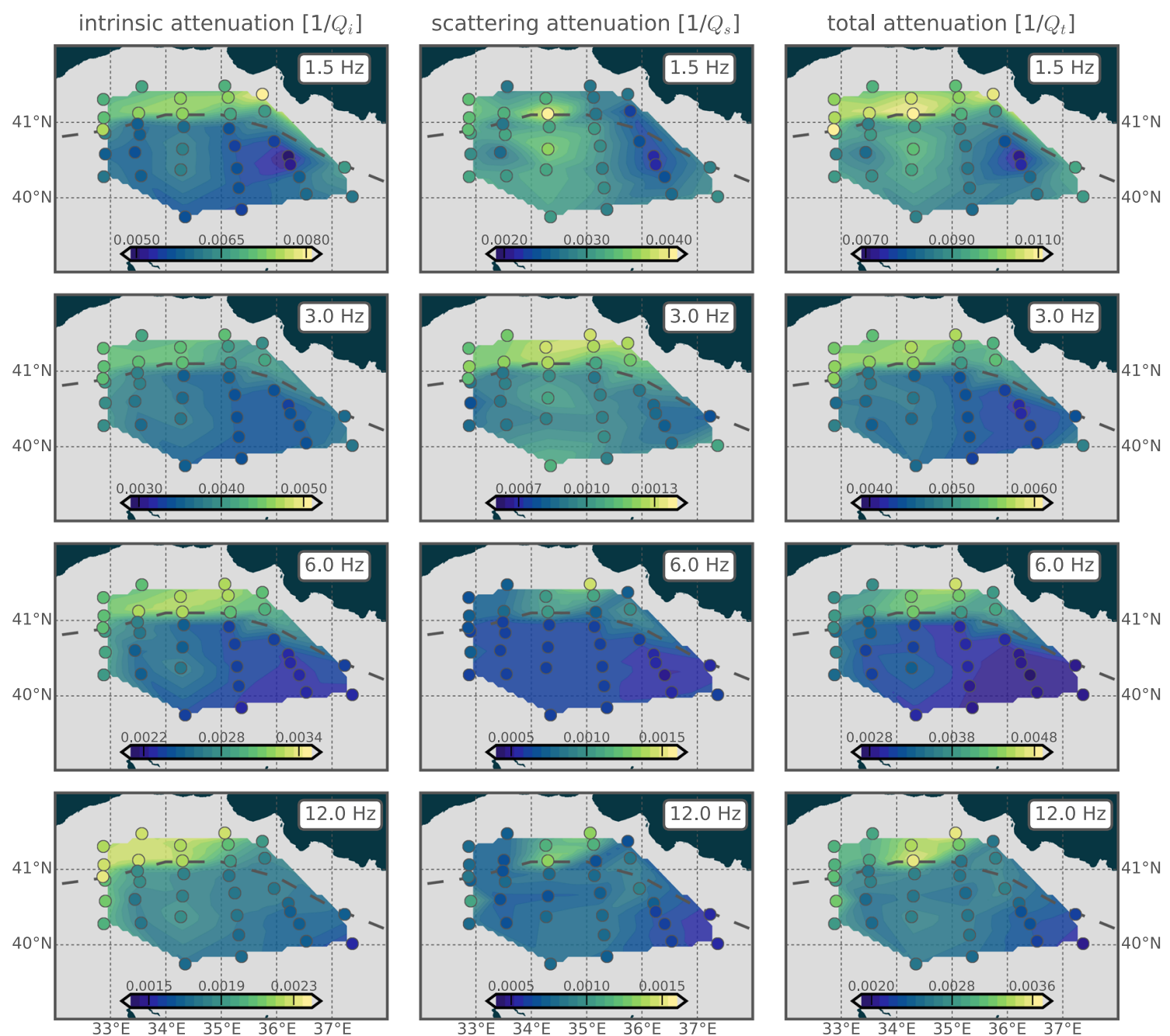

Fig. 6 Seismic intrinsic (left), scattering (middle), and total attenuation (right) in the study region represented by the inverse of the quality factors $\left(Q_{i}^{-1}, Q_{s}^{-1}\right.$, and $\left.Q_{t}^{-1}\right)$ for the four different investigated frequency bands (increasing frequency from top to bottom). Blueish colors indicate weaker attenuation, and yellowish colors represent stronger attenuation. Circles represent the attenuation values at the different stations, and values in between stations are interpolated plements of this manuscript or to Sato et al. (2012) or Rachman et al. (2015). The lateral variations of intrinsic attenuation exhibit clear visible differences between parts north and south of the NAFZ in all investigated frequency bands. This profound contrast marks the surface boundary of the NAFZ between two major tectonic units, the Çankırı Basin and the Central Pontides in the study area. Seismic energy loss due to the anelastic processes or internal friction during wave propagation is strongly controlled by temperature (Cormier 2011). Eulenfeld and Wegler (2017) observed a clear dependency of $Q_{i}^{-1}$ on temperature in the contiguous United States, with higher attenuation values being observed for the younger and hotter crust in the western part of the United States. In most parts of our study area, heat flow values vary around $70-80 \mathrm{~mW} / \mathrm{m}^{2}$. For a region in the north of the NAFZ in the Central Pontides (34-35 ${ }^{\circ}$ E, 40.7-41.3 ${ }^{\circ} \mathrm{N}$ ), higher heat flow values of around $130-140 \mathrm{~mW} / \mathrm{m}^{2}$ were reported by Akın et al. (2014). These higher heat flow values can be attributed to relatively shallow Curie point depths as well as the existence of hot water sources and hot springs in the northern part of the NAFZ. Such high values can be regarded as typical 
Fig. 7 Median absolute deviation in percent for $Q_{i}^{-1}$ (left) and $Q_{s}^{-1}$ (right) the individual inversion runs to the average values at the stations for the four different investigated frequency bands (increasing frequency from top to bottom). Blueish colors indicate smaller deviations from the average, and yellowish colors represent larger median absolute deviations
$1 / Q_{i}$ median absolute deviation [\%]
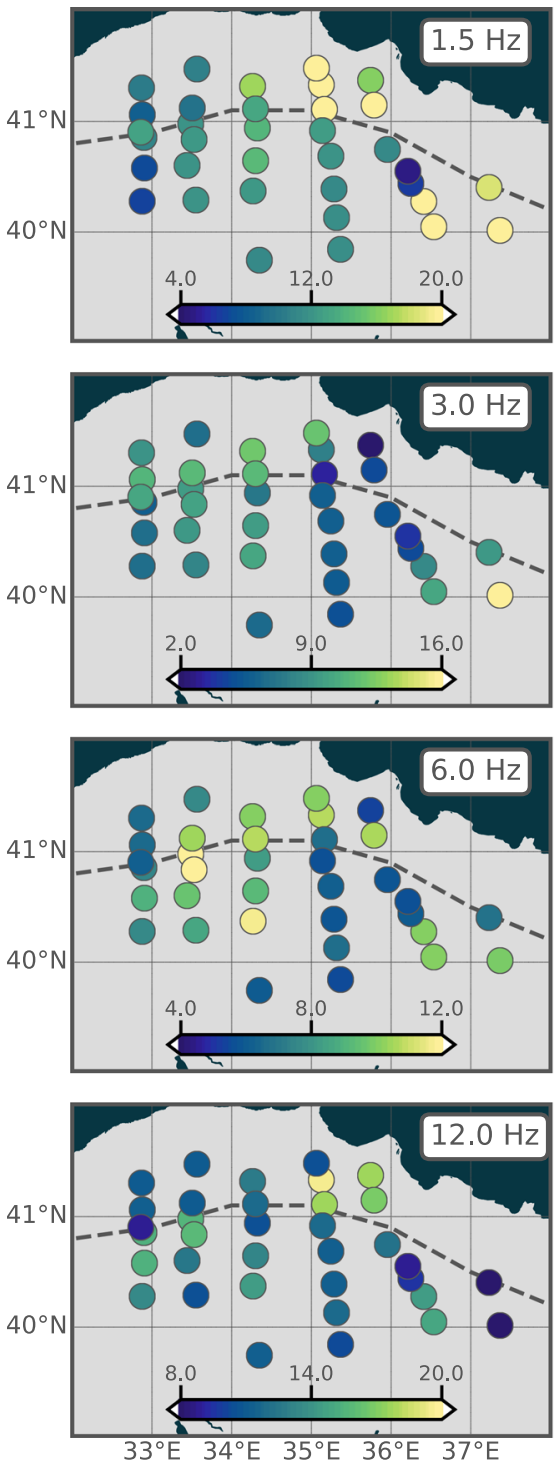

$1 / Q_{s}$

median absolute deviation [\%]
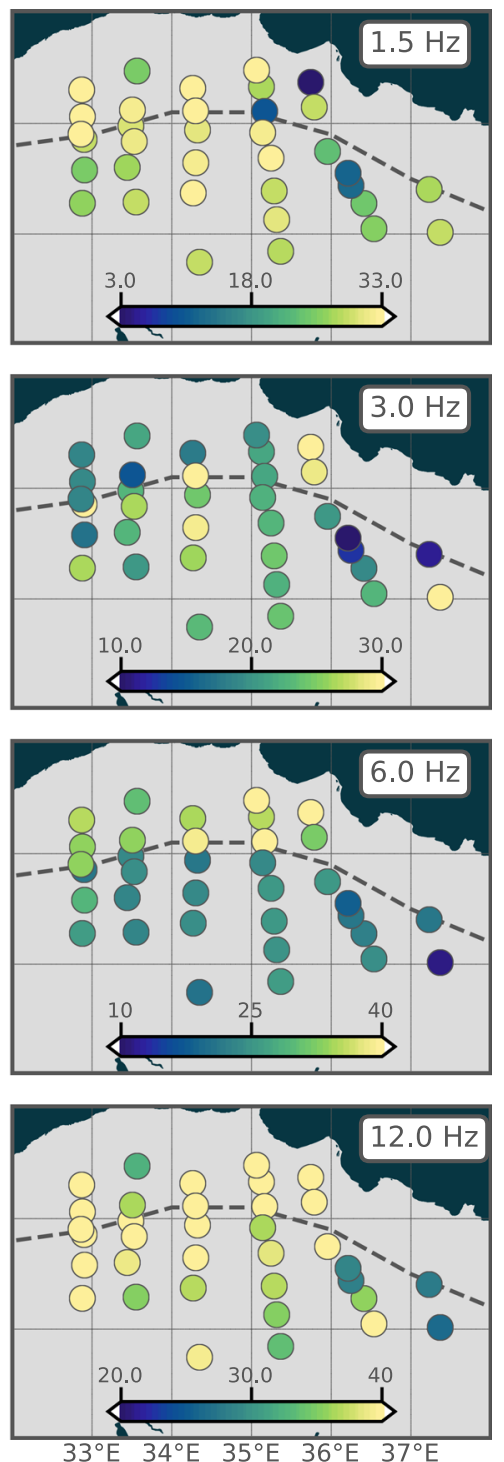

for a tectonically active region and hence can explain the high intrinsic attenuation values in the north of the NAFZ. In fact, high heat flow in this region is evident from the thick volcanic and volcano-sedimentary rocks that are cut by steeply dipping faults (Ustaömer and Robertson 2010). Besides this, an $\sim 4$-km sedimentary landfill that ranges from the Late Cretaceous to present age in the Çankırı Basin is also visible with high intrinsic attenuation variations in the south. Scattering attenuation only contributes to a small portion to the total attenuation in the investigated region and furthermore, lateral variations of scattering attenuation are small in the central part of the NAFZ. These two observations imply that crustal small-scale heterogeneities (for example fractured upper crustal rocks) only have a secondary influence on total seismic attenuation. Overall geological differences across the NAFZ between, i.e., upper Cretaceous ophiolitic melange and granitoids in Çankırı Basin (Robertson et al. 2009) and Permo-Carboniferous granitic magmatism, and Jurassic high-temperature low-pressure metamorphism in the central Pontides (Okay and 

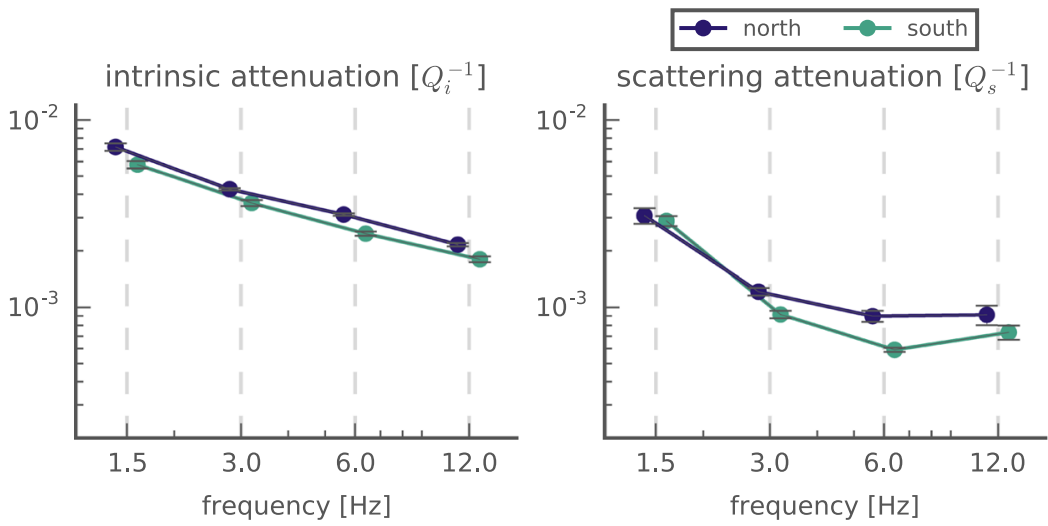

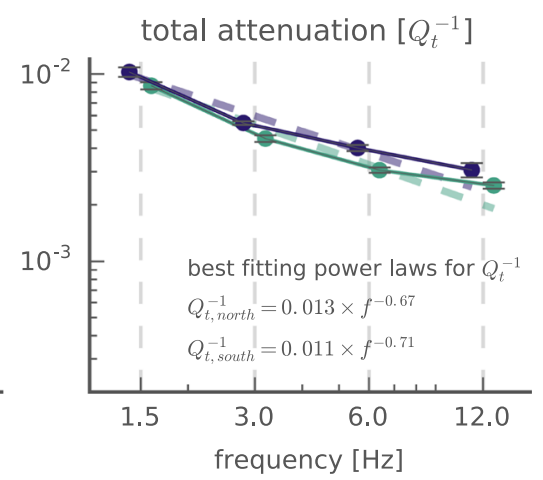

Fig. 8 Seismic attenuation in terms of $Q_{i}^{-1}, Q_{s}^{-1}$, and $Q_{t}^{-1}$ in the northern and southern region of the central part of the NAFZ. Dashed lines in the right part represent a best fitting power law for $Q_{i}^{t}$. Gray lines indicate the deviation in terms of median absolute deviation from the individual stations north and south of the NAFZ to the average values for the regions north and south of the NAFZ
Tüysüz 1999) appear to represent the distinct pattern in the variation of attenuation properties between the parts north and south of the NAFZ. Several recent seismological and geoelectrical observations and models, for example, fault guided head wave analysis and 3-D seismic velocity distributions following travel time or waveform tomography-derived imaging (Bulut et al. 2012; Yolsal-Çevikbilen et al. 2012; Fichtner et al. 2013a, b; Delph et al. 2015; Çubuk-Sabuncu et al. 2017), as well as 2D and 3D geoelectric models of the crust (Tank et al. 2005; Kaya et al. 2009, 2013) provided additional data on the evidence for lithological differences.

\section{Conclusions}

We apply an inversion approach using local earthquakes in the central NAFZ region to investigate intrinsic and scattering attenuation properties of the crust in the frequency range from 1.5 to $12.0 \mathrm{~Hz}$. Spatial variations of intrinsic and scattering attenuation maps at various frequency bands exhibit a strong dominance of intrinsic attenuation in the entire region. We observe high attenuation parameters for the central Pontides in the north with respect to the Çankırı Basin in the south. Heat flow measurements in the study area suggest that this distinct distribution of attenuation parameters across the NAFZ might have a thermal origin. Results are consistent with findings from previous studies on the isotropic and anisotropic seismic velocity structure in the region. Estimations of the source magnitude parameter in the inversion indicate a good agreement with local magnitudes within the earthquake catalog provided by the AFAD. The good fits between synthetic seismic envelopes calculated based on acoustic radiative transfer theory under the assumption of multiple isotropic and observed envelopes imply that our approach can be applied, even in this tectonically very complex setting.

Acknowledgments We highly appreciate the critical and helpful comments by the reviewers and thank the editor Mariano Garcia-Fernandez for handling the revision process. The python code used for carrying out the inverse modeling is available under the permissive MIT license and is distributed at https:// github.com/trichter/qopen. The facilities of IRIS Data Services, and specifically the IRIS Data Management Center, were used for access to seismic waveforms, related metadata, and/or derived products used in this study. IRIS Data Services are funded through the Seismological Facilities for the Advancement of Geoscience and EarthScope (SAGE) Proposal of the National Science Foundation under Cooperative Agreement EAR-1261681. Tuna Eken and Tuncay Taymaz acknowledge financial support from Alexander von Humboldt Foundation $(\mathrm{AvH})$ towards computational and peripherals resources.

Open Access This article is distributed under the terms of the Creative Commons Attribution 4.0 International License (http:// creativecommons.org/licenses/by/4.0/), which permits unrestricted use, distribution, and reproduction in any medium, provided you give appropriate credit to the original author(s) and the source, provide a link to the Creative Commons license, and indicate if changes were made. 


\section{References}

Aki K (1969) Analysis of the seismic coda of local earthquakes as scattered waves. J Geophys Res 74(2):615-631. https://doi.org/10.1029/JB074i002p00615

Aki K, Chouet B (1975) Origin of coda waves: source, attenuation, and scattering effects. J Geophys Res 80(23):33223342. https://doi.org/10.1029/JB080i023p03322

Akın U, Ulugergerli E, Kutlu S (2014) The assessment of geothermal potential of turkey by means of heat flow estimation. Bull Min Res Exp 149:201-210

Beck S, Zandt G (2005) Continental lithospheric deformation along a major strike-slip fault zone: the central North Anatolian Fault Zone, Turkey. International Federation of Digital Seismograph Networks

Bird P (2003) An updated digital model of plate boundaries. Geochem Geophys Geosys 4(3):1-52. https://doi.org/10. 1029/2001GC000252

Bulut F, Ben-Zion Y, Bohnhoff M (2012) Evidence for a bimaterial interface along the Mudurnu segment of the North Anatolian Fault Zone from polarization analysis of P waves. Earth Planet Sci Lett 327-328:17-22. https://doi.org/10.1016/j.eps1.2012.02.001

Calvet M, Margerin L (2013) Lapse-time dependence of coda Q: anisotropic multiple-scattering models and application to the Pyrenees. Bull Seismol Soc Am 103(3):1993-2010. https://doi.org/10.1785/0120120239

Carcolé E, Sato H (2010) Spatial distribution of scattering loss and intrinsic absorption of short-period $\mathrm{S}$ waves in the lithosphere of Japan on the basis of the multiple lapse time window analysis of Hi-net data. Geophys J Int 180(1):268290. https://doi.org/10.1111/j.1365-246X.2009.04394.x

Chandrasekhar S (1960) Radiative transfer. Dover Publications, Inc, New York

Cormier VF (2011) Encyclopedia of solid earth geophysics: seismic, viscoelastic attenuation. Springer, Netherlands

Çubuk Y, Yolsal-Çevikbilen S, Taymaz T (2014) Source parameters of the 2005-2008 Balâ-Sirapinar (central Turkey) earthquakes: implications for the internal deformation of the Anatolian Plate. Tectonophysics 635:125-153. https://doi.org/10.1016/j.tecto.2014.07.005

Çubuk-Sabuncu Y, Taymaz T, Fichtner A (2017) 3-D crustal velocity structure of western Turkey: constraints from fullwaveform tomography. Phys Earth Planet Inter 270:90112. https://doi.org/10.1016/j.pepi.2017.06.014

Dainty AM, Toksöz MN, Anderson KR, Pines PJ, Nakamura Y, Latham G (1974) Seismic scattering and shallow structure of the moon in Oceanus Procellarum. Moon 9(1):1129. https://doi.org/10.1007/BF00565388

Delph JR, Biryol CB, Beck SL, Zandt G, Ward KM (2015) Shear wave velocity structure of the Anatolian Plate: anomalously slow crust in southwestern Turkey. Geophys J Int 202(1):261-276. https://doi.org/10.1093/gji/ggv141

Dewey JF, Şengör AMC (1979) Aegean and surrounding regions: complex multiplate and continuum tectonics in a convergent zone. Geol Soc Am Bull 90:84-92. https://doi.org/10.1130/0016-7606(1979)90<84:AASRCM> 2.0.CO;2

Eken T, Mayeda K, Hofstetter A, Gök R, Örgülü G, Turkelli N (2004) An application of the coda methodology for moment-rate spectra using broadband stations in Turkey. Geophys Res Lett 31(11). https://doi.org/10.1029/ 2004GL019627

Eulenfeld T, Wegler U (2016) Measurement of intrinsic and scattering attenuation of shear waves in two sedimentary basins and comparison to crystalline sites in Germany. Geophys J Int 205(2):744-757. https://doi.org/10.1093/gji/ ggw035

Eulenfeld T, Wegler U (2017) Crustal intrinsic and scattering attenuation of high-frequency shear waves in the contiguous United States. J Geophys Res 122(6):4676-4690. https://doi.org/10.1002/2017JB014038

Fehler M, Hoshiba M, Sato H, Obara K (1992) Separation of scattering and intrinsic attenuation for the Kanto-Tokai region, Japan, using measurements of S-wave energy versus hypocentral distance. Geophys J Int 108(3):787-800. https://doi.org/10.1111/j.1365-246X.1992.tb03470.x

Fichtner A, Saygin E, Taymaz T, Cupillard P, Capdeville Y, Trampert J (2013a) The deep structure of the North Anatolian Fault Zone. Earth Planet Sci Lett 373:109-117. https://doi.org/10.1016/j.epsl.2013.04.027

Fichtner A, Trampert J, Cupillard P, Saygin E, Taymaz T, Capdeville Y, Villasenor A (2013b) Multiscale full waveform inversion. Geophys J Int 194(1):534-556. https://doi. org/10.1093/gji/ggt118

Gaebler PJ, Eulenfeld T, Wegler U (2015a) Seismic scattering and absorption parameters in the W-Bohemia/Vogtland region from elastic and acoustic radiative transfer theory. Geophys J Int 203(3):1471-1481. https://doi.org/10.1093/ gji/ggv393

Gaebler PJ, Sens-Schönfelder C, Korn M (2015b) The influence of crustal scattering on translational and rotational motions in regional and teleseismic coda waves. Geophys $\mathbf{J}$ Int 201(1):355-371. https://doi.org/10.1093/gji/ggv006

Gans CR, Beck SL, Zandt G, Biryol CB, Ozacar AA (2009) Detecting the limit of slab break-off in central Turkey: new high-resolution Pn tomography results. Geophys J Int 179(3):1566-1572. https://doi.org/10.1111/j.1365-246X. 2009.04389.x

Gök R, Kaviani A, Matzel EM, Pasyanos ME, Mayeda K, Yetirmishli G, El-Hussain I, Al-Amri A, Al-Jeri F, Godoladze T, Kalafat D, Sandvol EA, Walter WR (2016) Moment magnitudes of local/regional events from 1D coda calibrations in the broader Middle East Region. Bull Seismol Soc Am 106(5):1926-1938. https://doi.org/10.1785/0120160045

Gusev A, Abubakirov I (1987) Monte-Carlo simulation of record envelope of a near earthquake. Phys Earth Planet Int 49(1):30-36. https://doi.org/10.1016/0031-9201(87) 90130-0

Hoshiba M (1993) Separation of scattering attenuation and intrinsic absorption in Japan using the multiple lapse time window analysis of full seismogram envelope. J Geophys Res 98(B9):15809-15824. https://doi.org/10.1029/ 93JB00347

Kaya T, Tank SB, Tunçer MK, Rokoityansky II, Tolak E, Savchenko T (2009) Asperity along the North Anatolian Fault imaged by magnetotellurics at Düzce, Turkey. Earth Planets Space 61(7):871-884. https://doi.org/10.1186/ BF03353198

Kaya T, Kasaya T, Tank SB, Ogawa Y, Tunçer MK, Oshiman N, Honkura Y, Matsushima M (2013) Electrical 
characterization of the North Anatolian Fault Zone underneath the Marmara Sea, Turkey by ocean bottom magnetotellurics. Geophys J Int 193(2):664-677. https://doi.org/10.1093/gji/ggt025

Kaymakçı N, White SH, Vandijk PM (2000) Tectonics and magmatism in Turkey and the surrounding area, Geological Society of London, London, chap Paleostress inversion in a multiphase deformed area : kinematic and structural evolution of the Cankiri basin, Central Turkey : Part 1. Northern area, pp 295-323

Laigle M, Becel A, de Voogd B, Hirn A, Taymaz T, Ozalaybey S (2008) A first deep seismic survey in the Sea of Marmara: deep basins and whole crust architecture and evolution. Earth Planet Sci Lett 270(3):168-179. https://doi.org/10.1016/j.epsl.2008.02.031

Licciardi A, Eken T, Taymaz T, Agostinetti NP (2018) Seismic anisotropy in central North Anatolian Fault Zone and its implications on crustal deformation. Phys Earth Planet Inter 277:99-112. https://doi.org/10.1016/j.pepi.2018.01.012

Mayeda K, Walter WR (1996) Moment, energy, stress drop, and source spectra of western United States earthquakes from regional coda envelopes. J Geophys Res 101(B5):1119511208. https://doi.org/10.1029/96JB00112

Mayeda K, Malagnini L, Phillips WS, Walter WR, Dreger D (2005) 2-D or not 2-D, that is the question: a northern California test. J Geophys Res 32(12). https://doi.org/10.1029/2005GL022882

Okay AI, Tüysüz O (1999) Tethyan sutures of northern Turkey. Geol Soc London 156(1):475-515. https://doi.org/10.1144/ GSL.SP.1999.156.01.22

Paasschens JCJ (1997) Solution of the time-dependent Boltzmann equation. Phys Rev E 56:1135-1141. https://doi.org/ 10.1103/PhysRevE.56.1135

Pasyanos ME, Gök R, Walter WR (2016) 2D variations in coda amplitudes in the Middle East. Bull Seismol Soc Am 106(5):1915-1925. https://doi.org/10.1785/0120150336

Phillips WS, Mayeda KM, Malagnini L (2014) How to invert multi-band, regional phase amplitudes for 2-D attenuation and source parameters: tests using the USArray. Pure Appl Geophys 171(3):469-484. https://doi.org/10.1007/s00024013-0646-1

Przybilla J, Korn M (2008) Monte Carlo simulation of radiative energy transfer in continuous elastic random media-threecomponent envelopes and numerical validation. Geophys J Int 173(2):566-576. https://doi.org/10.1111/j.1365-246X. 2008.03747.x

Rachman AN, Chung TW, Yoshimoto K, Son B (2015) Separation of intrinsic and scattering attenuation using single event source in South Korea. Bull Seismol Soc Am 105(2A):858872. https://doi.org/10.1785/0120140259

Ristau J, Rogers GC, Cassidy JF (2003) Moment magnitudelocal magnitude calibration for earthquakes off Canada's West Coast. Bull Seismol Soc Am 93:2296-2300. https://doi.org/10.1785/0120030035

Robertson A, Parlak O, Koller F (2009) Tethyan tectonics of the Mediterranean region: some recent advances. Tectonophysics 473(1):1-282
Ryzhik L, Papanicolaou G, Keller JB (1996) Transport equations for elastic and other waves in random media. Wave Motion 24(4):327-370

Sato H, Fehler MC, Maeda T (2012) Seismic wave propagation and scattering in the heterogeneous Earth: second edition. Springer, Berlin

Sens-Schönfelder C, Wegler U (2006) Radiative transfer theory for estimation of the seismic moment. Geophys $\mathrm{J}$ Int 167(3):1363-1372. https://doi.org/10.1111/j.1365-246X. 2006.03139.x

Sens-Schönfelder C, Margerin L, Campillo M (2009) Laterally heterogeneous scattering explains Lg blockage in the Pyrenees. J Geophys Res 114(B7):1-19. https://doi.org/10.1029/2008JB006107

Sertcelik F, Guleroglu M (2017) Coda wave attenuation characteristics for North Anatolian Fault Zone, Turkey. Open Geosci 9:480-490. https://doi.org/10.1515/geo-20170037

Tank SB, Honkura Y, Ogawa Y, Matsushima M, Oshiman N, Tunçer MK, Çelik C, Tolak E, Işikara AM (2005) Magnetotelluric imaging of the fault rupture area of the 1999 İzmit (Turkey) earthquake. Phys Earth Planet Inter 150(1):213225. https://doi.org/10.1016/j.pepi.2004.08.033

Taymaz T, Jackson J, Westaway R (1990) Earthquake mechanisms in the Hellenic Trench near Crete. Geophys J Int 102(3):695-731. https://doi.org/10.1111/j.1365-246X. 1990.tb04590.x

Taymaz T, Westaway R, Reilinger R (2004) Active faulting and crustal deformation in the Eastern Mediterranean region. Tectonophysics 391:1-374

Taymaz T, Wright TJ, Yolsal S, Tan O, Fielding E, Seyitoglu G (2007) Source characteristics of the 6 June 2000 Orta-Çankırı (central Turkey) earthquake: a synthesis of seismological, geological and geodetic (InSAR) observations, and internal deformation of the Anatolian Plate. Geol Soc London, Spec Publ 291(1):259-290. https://doi.org/10.1144/SP291.12

Turner JA, Weaver RL (1994) Radiative transfer of ultrasound. J Acoust Soc Am 96(6):3654-3674. https://doi.org/10.1121/ 1.410586

Ustaömer T, Robertson AHF (2010) Late Palaeozoic-Early Cenozoic tectonic development of the Eastern Pontides (Artvin area), Turkey: stages of closure of Tethys along the southern margin of Eurasia. Geol Soc Lond Spec Publ 340(1):281-327. https://doi.org/10.1144/SP340.13

Vanacore EA, Taymaz T, Saygin E (2013) Moho structure of the Anatolian Plate from receiver function analysis. Geophys J Int 193:329-337. https://doi.org/10.1093/gji/ggs107

Weaver R (1990) Diffusivity of ultrasound in polycrystals. J Mech Phys Solids 38(1):55-86. https://doi.org/10.1016/ 0022-5096(90)90021-U

Wegler U, Lühr BG (2001) Scattering behaviour at Merapi volcano (Java) revealed from an active seismic experiment. Geophys J Int 145(3):579-592. https://doi.org/10.1046/j. 1365-246x.2001.01390.x

Yolsal-Çevikbilen S, Biryol CB, Beck S, Zandt G, Taymaz T, Adiyaman HE, Özacar AA (2012) 3-D crustal structure 
along the North Anatolian Fault Zone in north-central Anatolia revealed by local earthquake tomography. Geophys J Int 188(3):819-849. https://doi.org/10.1111/j.1365-246X. 2011.05313.x

Yoo SH, Rhie J, Choi H, Mayeda K (2011) Coda-derived source parameters of earthquakes and their scaling relationships in the Korean Peninsula. Bull Seismol Soc Am 101(5):23882398. https://doi.org/10.1785/0120100318
Zeng Y (1993) Theory of scattered P- and S-wave energy in a random isotropic scattering medium. Bull Seismol Soc Am 83(4):1264-1276

Publisher's note Springer Nature remains neutral with regard to jurisdictional claims in published maps and institutional affiliations. 